\title{
Ritual, recursos y pasión en la política: un análisis situacional de una contienda electoral en el occidente de México
}

\author{
Edwin Rap* \\ UNIVERSIDAD DE WAGENINGEN
}

Este artículo contribuye a un cuerpo creciente de literatura que cuestiona los enfoques centrados en el Estado para analizar la política, adoptando una perspectiva más descentrada y cultural. Se hace esto por medio de la presentación de un análisis situacional y etnografía detallada de una contienda electoral local en el occidente de México. El análisis de este evento como un performance (representación) cultural ilustra la presentación dramática de actos culturalmente significativos como parte central de una conducta electoral, y muestra como juegan su parte en la política: la vida organizacional cotidiana, los flujos de recursos, los rituales públicos y la pasión. Que tales actos no son meramente simbólicos se muestra por lo que ocurre detrás del telón de los rituales políticos: un grupo político se apropia de una Asociación de Usuarios del Agua y se apoya en su personal, sus instalaciones, recursos y relaciones de poder para su campaña política. Tales prácticas también indican los resultados no anticipados de las recientes reformas de descentralización administrativa. Las nuevas organizaciones de productores creadas por estas reformas para administrar tareas de manera más eficiente, que previamente correspondían al gobierno, son usadas políticamente, no simplemente de manera instrumental sino culturalmente específica.

(Ritual político, administración de recursos, reforma administrativa, transferencia del manejo de riego, caciquismo, cultura política, performance/representación)

\footnotetext{
*Edwin.Rap@wur.nl
} 


\section{INTRODUCCIÓN}

n una contienda electoral local en Nayarit, México, el candi-
dato político y organizador del evento, Alfredo Núnez, ${ }^{1}$ está
en la cocina. ¿Qué es lo que trae a tal prominente actor político en la cúspide de su campaña a este lugar? Un auxiliar sirve en platos una especialidad culinaria de frijoles charros que luego pone en las manos de Núnez y algunos de sus colaboradores. Atípicamente no hay mujeres en la cocina para esta tarea. Afuera, se ha congregado una muchedumbre de seguidores de Núnéz. Con cuidadoso ceremonial Núñez sirve personalmente los platos a varios de sus votantes potenciales.

Con este acto dramático, Núñez representa una preferencia regional populista, de acuerdo a la cual los políticos tienen que mostrar que están sirviendo a las necesidades individuales de sus votantes de una manera personal y culturalmente apreciada. Esta corta vińeta es apta para ilustrar el argumento central de este artículo: la importancia del performance (representación) cultural en la política mexicana, o en otras palabras, la representación dramática de actos culturalmente significativos como parte central de las prácticas políticas y electorales.

Esta escena es sólo una toma del análisis situacional de la contienda electoral que presento enseguida. Este evento político es interpretado aquí como una representación cultural, como "el show"

${ }^{1}$ Una primera versión de este artículo ha sido publicada en la revista Journal of Latin American Studies (Rap 2007). Quiero agradecer a Horacia Fajardo por hacer una excelente traducción de este artículo. Los dos comentaristas, de Relaciones. Estudios de Historia y Sociedad, hicieron un trabajo con mucha dedicación que ha mejorado este artículo. Entre 1996 y 2000, recibí apoyo muy apreciado de varias personas en el Colegio de Michoacán como Brigitte Boehm de Lameiras (que en paz descanse), Esteban Barragán López, Luz Nereida Pérez Prado, José Luis Seefoó Luján, Sergio Zendejas Romero y otros. Además, desarrollé un círculo de amigos antropólogos en Zamora con quienes disfruté varias discusiones y fiestas: Zulma, Blanca, Francisco, Eduardo, Alma y otros. Con cierto romanticismo recuerdo las fiestas en que aprendí a bailar, empezando con el merengue y continuando con el tequila. En la Universidad Autónoma de Nayarit tuve el privilegio de recibir el apoyo y la amistad de Omar Wicab y Emma Sifuentes.

Los nombres de las personas de este artículo serán ficticios cuando sea necesario proteger sus identidades. 
que expresa y visualiza lo cultural (Munro 1999), en maneras que apelan a la imaginación popular. Además de que apunta a los aspectos discursivos y visuales de la conducta política que es actuada en el "escenario" o para la imagen pública, el análisis se enfoca también en lo que ocurre detrás de las escenas del ritual político. De esta manera, el artículo enfatiza el papel que tiene en la política el ritual público y la pasión, y muestra también cómo afecta la vida organizacional cotidiana y la disposición de los recursos.

El evento político analizado aquí es el producto de las reformas neoliberales implementadas a lo largo de América Latina durante las últimas tres décadas, incluyendo descentralización política, pluralización democrática y desregulación agrícola. La política mexicana de transferencia de manejo de riego (TMR) es típica de este enfoque ya que implica el traspaso de la administración de los distritos de riego desde la burocracia federal a las Asociaciones de Usuarios de Agua locales (AUA). Alfredo Núñez es el presidente de una de estas asociaciones. Un análisis detallado de las actividades en las cuales se involucra su grupo indica el problema de los modelos administrativos que subyacen a estas reformas: estos modelos toman el manejo de recursos como un acto técnico de provisión de servicios, vacío de cultura y de política. Sin embargo, los recursos de las AUA se movilizan de acuerdo a maneras culturalmente atractivas y establecidas de enganchamiento en la política, de manera legítima como ilegítima. En suma, el estudio de esta reforma confirma el valor de una perspectiva cultural sobre la política de cara al cambio político y administrativo.

Al inicio de los noventa del siglo pasado, el gobierno de Carlos Salinas de Gortari (1988-1994) realizó reformas radicales a los sistemas existentes para el manejo del riego, como parte de un paquete más amplio de reformas neoliberales. Con el apoyo de agencias internacionales financieras, el gobierno mexicano dirigió la forma de introducir nuevas reformas en la administración del agua. Un ejemplo de las medidas aprobadas es la TMR, una nueva ley sobre el agua, una fijación activa de precios de agua y un mercado de agua más liberalizado. En este contexto, el programa de TMR de México llega a ser internacionalmente reconocido como un "éxito" y fue propaga- 
do como un modelo para otros países que buscaban mejorar el manejo del riego y reducir el gasto público (Rap 2006; 2008).²

En el estado de Nayarit, un pequeño estado de México donde tuvo lugar la contienda electoral que se analiza en este artículo, la transferencia del manejo del riego es sólo uno de una serie de los complicados cambios que ocurrieron durante los noventa (véase la figura 1). Como en muchas otras partes de México, los siguientes tres cambios reordenaron el paisaje organizacional y crearon una arena política más competitiva: primero, aumentó la importancia de los partidos políticos de oposición y el decline de la hegemonía del Partido Revolucionario Institucional (PRI). Este escenario debilitó las organizaciones corporativistas del PRI como la Confederación Nacional Campesina (CNC) y las representaciones municipales últimas (СMC). Segundo, el repliegue burocrático de la Secretaría de Agricultura ocasionó que ciertas responsabilidades de algunas áreas políticas fueran asumidas por nuevos cuerpos, como las nuevas asociaciones de productores, tales como las AUA en los distritos de riego y Sanidad Vegetal. Tercero, la desregulación de las políticas agrícolas afectó la economía política de la producción del tabaco, por mucho, el principal motor del desarrollo económico y primera fuente de ingresos, control y organización política en Nayarit. Esto indujo al desmantelamiento de Tabamex, la paraestatal para la producción del tabaco, a la reentrada en el proceso de producción de las empresas multinacionales tabacaleras y al establecimiento de la organización de productores de tabaco, Asociación Rural de Interés Colectivo (ARIC).

\section{Representación cultural en la Política Mexicana}

El discurso político tecnocrático presenta a la reforma administrativa como políticamente neutral y carente de cultura. Sin embargo, aquí se argumenta que tales reformas llegan a incorporarse a repertorios culturales específicos y que su incorporación altera el flujo y distribución de poder y recursos políticos de maneras que tienden a ser impredecibles. En México esto se refuerza por un movimiento

\footnotetext{
${ }^{2}$ He discutido con amplitud este modelo en Rap (2006; 2008).
} 
generalizado hacia la descentralización (Barracca 2005). La TMR es un ejemplo de tal desarrollo.

Estos cambios políticos indican la relevancia del análisis académico reciente del régimen "descentralizado" (Rubin 1997). Hace una década Jeffrey Rubin cuestionó la perspectiva sobre la política mexicana centrada en el Estado y la tendencia a sobrestimar la presencia del corporativismo estatal en el México regional. $\mathrm{Al}$ analizar lugares y flujos de poder fuera del centro político se amplía el concepto de política, la cual anteriormente estaba restringida al Estado y los partidos. Rubin acierta cuando coloca la cultura, las prácticas diarias de las agrupaciones de la sociedad civil y la región como un lugar político, dentro de las discusiones acerca del poder y del Estado. La atención analítica, por lo tanto, cambió a las prácticas locales y regionales de regulación en el contexto de los proyectos de la formación del Estado y hacia los efectos específicos que éstos generaron en la cultura política de las diferentes regiones de México (Aitken 1999).

Pero en marcado contraste hacia los enfoques que subrayan especificidades locales, las reformas neoliberales parecen introducir un patrón organizacional universal. En el área rural de México, estas reformas han liberado dominios políticos anteriormente institucionalizados por el ámbito estatal y que ahora son ocupados por "nuevos" actores organizacionales. Una ideología neoliberal y tecnocrática propone a estos actores como agentes racionales y empresariales que responden a la técnica local o a las exigencias del mercado. Sin embargo, esto pasa por alto a los "titulares ambiciosos" que buscan controlar tales áreas políticas (Snyder 1999).

Incluso desde una perspectiva centrada en el Estado, no es sorpresiva la emergencia de actores locales que aspiran a controlar las nuevas instituciones. La literatura histórica sobre la política local y regional en el México rural se ha enfocado en el papel central del cacique (o jefe político local). En el periodo de la centralización política posterior a la Revolución Mexicana de 1910-1917, el Estado tuvo alcance limitado en el nivel local. Para incorporar la periferia rural, el centro político necesitaba intermediarios. Estos caciques fueron líderes conectados a patrocinadores políticos de altos niveles y mantuvieron su poder por medio de asegurar recursos guberna- 
mentales a las comunidades que ellos representaban (Gledhill 1996). Inicialmente, con frecuencia fueron agraristas o militares que proveían tierra o protección para sus clientes. Al paso de las décadas, las esferas de operación de tales líderes pasaron a ser agencias burocráticas y uniones oficiales (Peña 1986). Como intermediarios efectivos, los caciques llenaron un papel estructural en el orden político al vincular los diferentes niveles de la organización social y política. Esta clase de intermediación depende de la existencia de un Estado que monopolice y controle la dirección de los flujos de poder y recursos hacia la periferia.

Entonces la cuestión es: ¿qué ocurre en una era neoliberal cuando los recursos vienen a estar cada vez más sujetos a la competencia? (Hernández Rodriguez 2005). Tal transformación permite derivar el poder, local y regional, a través del control sobre las instituciones y sus recursos y por ello ser legitimados a través de rituales públicos. Entender este proceso requiere un amplio entendimiento de la cultura política mexicana. La persistencia del cacique en la política mexicana no puede ser completamente apreciada desde el punto de vista estructural sobre la intermediación ya que descuida las formas culturales, las prácticas y materiales que los actores sociales usan para articular relaciones políticas cambiantes (Thompson 1997). Es a través de estos repertorios políticos que la autoridad política se reproduce, se mantiene y se expande. Es en este proceso también que el aspecto interpretativo de la política se refuerza o suprime. Una segunda dimensión descuidada son los aspectos imaginarios, interpretativos y discursivos del caciquismo (Pansters 2005). Ambos aspectos son ilustrados en una rica etnografía por Pieter De Vries (2002). Su trabajo ilustra el placer que exhibe un cacique en la corrupción, las habilidades para organizar el disfrute público y las historias y rumores alimentados activamente acerca de su carácter violento y sus escapadas sexuales. Estos actos interpretativos y narrativos contribuyen a la construcción del cacique en la imaginación popular como un elemento dominante y corrupto, pero inevitable en la cultura política mexicana. El cacique se presenta habilidosamente como un mediador indispensable entre la gente y el centro político (Nuijten 2003). Esto responde a una continua búsqueda popular por "la relación 
correcta" y promueve la imaginación del centro como "la fuente real del poder", mientras que oscurece el conjunto difuso de las prácticas descentralizadoras subyacentes.

Más ampliamente, la idea del drama juega un papel significante en el análisis sociológico. El análisis de la conducta política como forma de representación cultural encuentra su inspiración en la Escuela de Manchester y su trabajo acerca del significado cultural del ritual público y el drama social (Gluckman 1958; Velsen 1967). ${ }^{3}$ Otra fuente de influencia se origina en los estudios del folklore, el uso del lenguaje, el ritual y el teatro (Parkin et al. 1996). Sin embargo, mi preocupación aquí no son "cuáles aspectos del teatro se deslizan en la vida cotidiana" (Goffman 1959). Más bien es la observación de Irving Goffman de que "cuando un individuo se presenta frente a otros, sin conocerlo y sin desearlo proyecta una definición de la situación, de la cual la concepción de sí mismo es una parte importante" (ibidem 242). En consecuencia, algunos aspectos de la actividad públicamente desempeñada son "acentuados expresivamente y otros aspectos, que pudieran desacreditar la primera impresión, son suprimidos" (ibidem 111). Estas pistas pueden ser aplicadas a un amplio rango de escenarios políticos y organizacionales.

Por ejemplo, Rolland Munro ha identificado ciertas formas organizacionales como representación cultural (Munro 1999). Muestra como algunos gerentes construyen sus representación culturales para hacerse visibles a sí mismos uno para el otro, tanto como miembros de un grupo o como administradores individuales que son identificables como los que "están en control". Ya que ellos tratan de mostrar a los otros lo que están haciendo o han hecho; toman acciones sobre un aspecto "interpretado para una audiencia” (Turner 1987,74$)$. Una comparación cruda sugiere que los administradores ingleses estarán ansiosos de exhibir una sensación de control a través de su trabajo considerado como exitoso, mientras que los po-

${ }^{3}$ En un estudio clásico, Max Gluckman estudió los roles dramáticos de los zulúes y los europeos en las celebraciones colectivas y rituales por la apertura de un puente en Zululand. Desde el "análisis situacional" de esta ocasión pública, infirió pistas teóricas con respecto a la estructura social y los procesos de cambio que vivía la sociedad. Véase Max Gluckman (1958) y van Velsen (1967). 
líticos latinoamericanos populistas desearían apadrinar las muy bien atendidas festividades para alcanzar el mismo efecto. "Un énfasis en la representación cultural se enfoca en cumplir con las maneras en que la gente hace el material cultural visible y disponible" (Munro 1999, 619). Por ejemplo. Akhil Gupta demostró que incluso un soborno es una práctica cultural que requiere un alto grado de interpretación competente (Gupta 1995).

Como ritual, la representación cultural trata de convencer a los participantes del modo en que el mundo es. Más que ser una muestra opaca y vacía de la forma, se interesa en involucrar a la gente, no sólo racional, sino emocionalmente. Por esto es que el elemento festivo es importante, especialmente en los eventos electorales de México y de Latinoamérica, más generalmente. El disfrute colectivo de comida, bebida, música y danza libera el flujo de pasión. Por ejemplo, De Vries (2002) anota que "las políticas de disfrute" en México, y particularmente en el estado de Jalisco, incluyen la organización de fiestas y el reconocimiento del anhelo de comunidad por los ejidatarios. El arte de manejar gente implica que ellos lleguen a ser parte de un diseño más amplio, por ejemplo, con comida y bebida, grupos musicales y mariachis. Tal cultura del poder requiere de la voluntad de inmiscuirse en relaciones personales con ejidatarios y la habilidad para organizar modos públicos de disfrute (public modes of enjoyment) (De Vries 2002). Similarmente, Ben Fallaw (2002) demuestra que la "política húmeda" llegó a ser central para la cultura política en el estado de Yucatán para el tiempo de la Revolución mexicana. Él argumenta que el poder del alcohol fue la clave para que el socialismo yucateco pudiera movilizar el apoyo electoral y atraer a los hombres de las clases más bajas a las campañas y concentraciones políticas. El ritual y la oferta generosa de alcohol se convirtieron en una "fiesta húmeda". Fallaw argumenta perceptivamente que esto no debería ser una sorpresa dada la importancia cultural y ceremonial del alcohol, comida y música en las celebraciones populares de los festivales católicos en Latinoamérica (Beezley et al. 1994). Estos eventos electorales reflejan también una tradición católica particular del espectáculo que invocan múltiples sensaciones humanas para enganchar, educar y convertir a las masas. 
A pesar de su carácter celebrante, la representación cultural está "siempre inmersa en el juego del poder" y relaciones sociales y materiales concretos (Parkin et al. 1996). Particularmente, alrededor de las elecciones, los indicadores son altos, y ello acelera la presión para el desempeńo. Los candidatos experimentan gran necesidad de demostrar públicamente que ellos valen el apoyo financiero, político y electoral que solicitan. Los tiempos de la representación cultural son esenciales porque el impacto en la votación es limitado ya que hay muchos otros factores jugando su papel. Ello no significa que la representación cultural es todo en la política. Como lo mostraré después, está conectada íntimamente con la lucha por el poder, las relaciones y el control de los recursos. Sin el apoyo de los recursos materiales, las relaciones sociales y la guía hacia el poder, la representación cultural pierde su potencial, significado y dirección.

Por lo tanto, la contienda electoral descrita enseguida, no es un evento aislado, sino la conclusión de una serie de encuentros privados durante los meses precedentes, en los cuales el principal contendiente, Alfredo Núñez, construyó escrupulosamente una amplia coalición de apoyo. Su campaña culminó luego de tres mítines políticos en los cuales él asumió públicamente el liderazgo de la alianza, así como también movilizó, visualizó y midió el apoyo que había adquirido. El tercero y último en esta serie de mítines públicos, que fue seguido por las elecciones, se describe detalladamente enseguida.

La elección se hizo por el Comité Municipal de Campesinos (CMC) de la Costa del Pacífico de Nayarit, en el Occidente de México. Alfredo Núnez era el presidente de la AuA en la región y parte de un grupo político local, cuyo electorado se localiza en la Margen Izquierda del Río Santiago, parte de un distrito electoral en la municipalidad de Santiago Ixcuintla (véase figura 1). El pueblo, Villa Hidalgo, era el centro de poder para este grupo. Aquí el grupo controlaba varias organizaciones, entre las cuales se hallaba el módulo de riego de la Margen Izquierda. Gonzalo Pérez, un abogado local y gran terrateniente llegó a ser el primer presidente de la AUA, estableciéndose él mismo como un cacique local. La gente especuló siempre que el origen del bienestar, que respaldó su carrera política y la razón de que siempre portaba una pistola, se debía al transporte de 
FIgura 1: Margen Izquierda y Derecha del Río Santiago

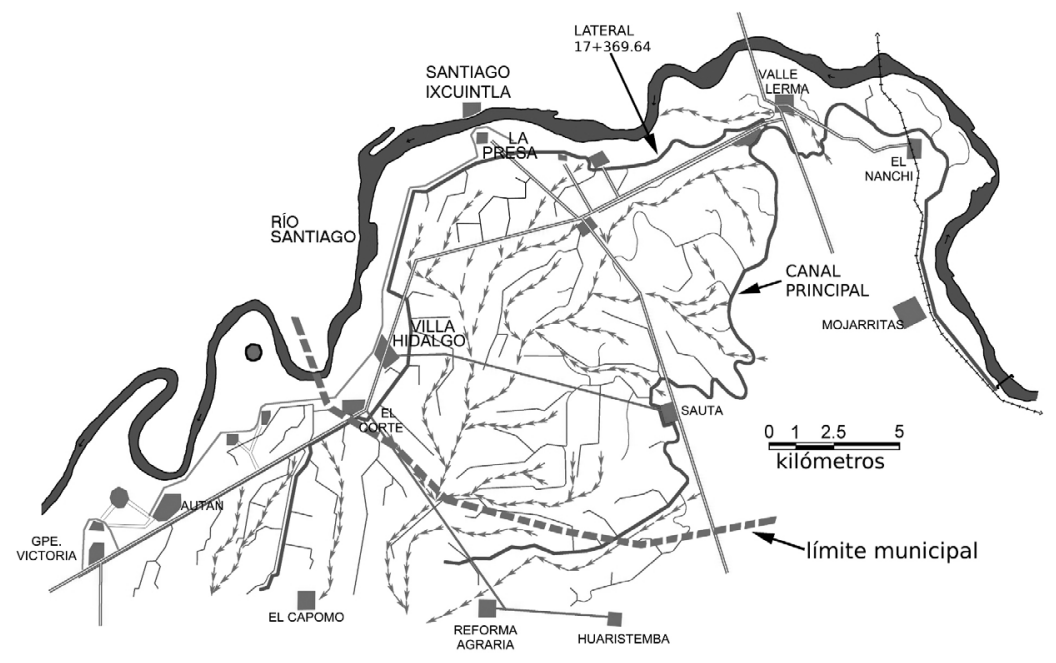

bienes ilícitos. En 1996, Gonzalo Pérez fue electo como diputado local del PRI. Posteriormente compró votos en las elecciones de la AUA para que su protegido, el tesorero y líder local Alfredo Núñez, llegara a ser presidente de la misma. Núnez siguió una senda similar a su patrocinador y pronto empezó a usar la AUA como plataforma política para promoverse a sí mismo para la presidencia del Comité Municipal de Campesinos (CMC). Esta organización corporativista formaría un escalón esencial para que Gonzalo Pérez llegara a ser presidente municipal de Santiago. Mientras tanto, habían contratado como administrador de la AUA a un viejo amigo y compadre de Pérez, Fernando Gutiérrez, y ubicado a varios clientes y aliados como parte del personal de aquélla. Este grupo político y su base organizacional tuvieron un papel importante en la contienda electoral.

\section{LA CONTIENDA ELECTORAL}

En una mañana de febrero de 1998, un mitin electoral tuvo lugar en la capital de Santiago Ixcuintla. En un desayuno para sus seguidores, Alfredo Núnez cerró su campańa por la presidencia de la or- 
ganización campesina, el CMC, que integra los 54 ejidos de la municipalidad de Santiago Ixcuintla. Cada tres ańos, estos ejidos son autorizados para enviar a cuatro comisionados para elegir a un nuevo Comité del CMC. ${ }^{4}$ Alfredo Núñez encabezaba la lista de miembros candidatos de un comité que él mismo había compilado entre los comisionados de los ejidos del municipio. ${ }^{5}$ La lista, registrada como la lista verde, era referida popularmente en la prensa local como "Unidad Campesina".

Alfredo Núñez preparó el día de las elecciones en un sitio al lado del río. El lugar consistía de un espacio al aire libre con una alberca y un edificio largo con un bar y una cocina al fondo. Se habían colocado cuidadosamente mesas y sillas de plástico para esperar más de un centenar de delegados ejidales, frente a una plataforma para los oradores. En alrededor de una hora, los seguidores de Núñez disfrutarían un desayuno y escucharían su charla antes de emitir su voto. Núnez y Mario Uribe estaban sentados ante una de las mesas. Uribe era la mano derecha de Núñez en el ejido Solorceño, su portavoz oficial, y miembro del Comité de la sección municipal de los productores de la Sanidad Vegetal. En los meses previos estuvo involucrado en la coordinación de la campaña de Núñez por la presidencia del смс. Símbolos claros identificaban al líder, su coalición y sus seguidores. Núnez, un hombre bajo, vestía una camisa verde, que coincidía con el color de la lista que el encabezaba y la bandera enarbolada en una asta cercana.

Los dos hombres estaban leyendo los periódicos locales. Los saludé y pregunté que decían los artículos. Núñez me pasó en silencio la edición matutina del periódico local, El Diario. Un artículo en la primera página anunciaba que habría elecciones ese día en el CMC entre dos grupos opositores. De acuerdo a El Diario, Núñez era apoyado por "líderes ejidales honestos" con una "vocación democrática",

${ }^{4}$ Se permite a cada uno de los 54 ejidos enviar al presidente, secretario y tesorero del Comisariado Ejidal y al presidente del Consejo de Vigilancia. Esto implica un total de 216 votos.

${ }^{5} \mathrm{La}$ asamblea ejidal elige un comité ejecutivo, consistente en los siguientes comisionados ejidales: un presidente o comisariado ejidal, un secretario y un tesorero. Además la asamblea elige al Consejo de Vigilancia. 
mientras que la lista roja representaba a los grupos más reaccionarios y desacreditados, apoyados por las organizaciones de los productores de tabaco, ARIC. Este grupo estaba encabezado por su patrocinador y expresidente, el corrupto Güero, y comprometía al actual presidente, Gerardo Soto y a su candidato Humberto Leal. De acuerdo al artículo, ellos era hombres que evocaban tristes recuerdos en la gente del campo. Núñez se veía confortable con estos reportajes favorables.

Desde su creación, al inicio de los noventa, la ARIC fue controlada por el grupo de su primer presidente, llamado popularmente El Güero. El Güero debía su carrera política a Don Emilio, el patriarca del partido dominante en Nayarit. La ARIC se estableció como una organización de nivel estatal para negociar el precio anual del tabaco con las cuatro principales multinacionales tabacaleras que operan en el estado. Llegó a ser una organización rica e influyente políticamente de tal manera que dominó las áreas productivas del tabaco y las organizaciones rurales en Nayarit. En el estado, el financiamiento de la ARIC para las campañas políticas de varios de los candidatos del PRI para el gobierno del estado fortaleció sus fortunas políticas. En el intercambio, la ARIC adquirió varias posiciones políticas, como diputaciones en el congreso del estado. El CMC en Santiago probó ser central para ello. Es decir, existió una conexión cercana entre la ARIC y el CMC, manifestada por el apoyo que ésta última recibió de la primera. Este patrón había continuado cuando la ARIC postuló a Humberto Leal como su nuevo candidato por la presidencia de la cмc. Como parte de su campańa, el grupo del Güero convocó el apoyo de una base selectiva que la ARIC había construido y financiado en la década precedente entre los líderes agrarios de los ejidos productores de tabaco. Sin embargo, esta base de apoyo había sido gradualmente erosionada. Por muchos años, la ARIC había sido incapaz de negociar precios del tabaco sustancialmente altos. ${ }^{6}$ Como resultado, la organización fue perdiendo credibilidad entre los productores y muchos pedían su remoción. Este

${ }^{6}$ Los precios del tabaco muy abajo de los precios oficiales del mercado mundial. La ARIC estuvo sujeta a acuerdos hechos entre el gobierno federal y estatal y las compañías tabacaleras. Más aún, ellas dependían económicamente de las compañías, y éstas no deseaban pagar precios más altos. 
decline en su popularidad fue explotado inteligentemente por su oponente político.

En los meses precedentes, Alfonso Núñez había atraído publicidad y apoyo popular al patrocinar una campaña de recriminación de periodistas y la prensa local contra su competidor Humberto Leal y contra la ARIC. Al mismo tiempo, estos artículos proyectaban una imagen favorable del liderazgo de Núnez. Este tipo de periódico local fue leído por muchos ejidatarios y campesinos políticamente informados y fue una fuente importante de noticias y opiniones. Evidentemente, no eran fuentes de noticias independientes. Los políticos locales pagaban a los reporteros para que publicaran sus versiones sobre las noticias como parte de la campaña electoral. Estos medios de comunicación proyectaban su desempeño público desde una posición favorable y modelaban las impresiones públicas acerca de los candidatos y sus oponentes. Esto formaba parte de la comunicación de sus desempeños culturales para una audiencia amplia. Para financiar tal campaña mediática se requería de una fuente de financiamiento persistente; para el caso Núñez, ésta se derivaba de la AUA.

Pero no sólo estuvieron involucrados los recursos financieros de la AUA. Durante las preparaciones del mitin, Núnez usó al personal de la AUA, sus recursos y redes más amplias para movilizar y atraer a los votantes. Alrededor de las ocho, Leopoldo, el asistente de mantenimiento de la AUA estacionó su camioneta pick up que condujo desde la AUA. En la caja posterior había enormes cazuelas con platillos de carne, tortillas y frijoles, que llevó hasta la cocina. Le pregunté cuánto tiempo había empleado en acarrear el desayuno. Me dijo que se había levantado a las 4:30 am, para recoger a los delegados ejidales y seguidores de Núnez desde los ranchos más lejanos de la municipalidad. Su camioneta había sido sobrecargada y estimaba que había transportado entre 50 y 100 personas. Ellos no habrían venido de otra manera, explicó, ya que no habrían tenido maneras personales de transporte y sus ejidos no tenían servicio de transporte público. La oportunidad de hacer sus compras en Santiago y la posibilidad de obtener una buena comida y bebida en el día electoral persuadió a muchos de ellos a acudir. Mientras que platicaba con Leopoldo, otros empleados de la AUA empezaron a llegar. Habían recogido y 
transportado a otros comisionados de los ejidos en las cajuelas de las camionetas de la AUA. Muchos de ellos usaban sombreros o cachuchas de béisbol y vestidos ordinarios, que indicaban sus modestos antecedentes campesinos. Ellos se sentaron en las mesas. Casi todos eran hombres (pocos de los comisionados ejidales con derecho a votar eran mujeres). Sin embargo, algunas mujeres llegaron. Gradualmente el lugar tomó un aire de muchedumbre.

Algunos líderes y campesinos activistas bien conocidos de la región llegaron por sus propios medios. Núñez había logrado claramente al reunir una amplia coalición de líderes y activistas políticos, grupos de productores y organizaciones que le apoyaron durante su campaña. Algunos de los comisionados ejidales presentes habían apoyado activamente a Núñez durante su campaña por el CMC y ahora estaban registrados como parte de su planilla; esperaban obtener una posición dentro del CMC una vez que Núñez ganara las elecciones. Por ejemplo, Bruno Nava, el comisionado ejidal de Pozo de Ibarra fue asignado más tarde como presidente del "comercio del frijol" para explorar nuevas oportunidades de vender este grano a un mejor precio, para lo cual necesitaría conseguir apoyo político y recursos gubernamentales. Otros habían negociado favores personales de Núñez. Por ejemplo, un activista de Santiago consiguió un empleo para su hijo como asistente de la AUA. Es decir, con el fin de construir una alianza de apoyo e incluir a los líderes influyentes, Núñez prometió posiciones y favores sustanciales durante la fase preparatoria de las elecciones. Fue capaz de hacer esto por su posición como presidente de la AUA.

Otro de los colaboradores de Núñez fue Nacho Xavier, el entonces presidente de Sanidad Vegetal y colega de Mario Uribe. Una semana antes del mitin de la campaña, él había dado un discurso a favor de la alianza con Núñez y usado sus habilidades oratorias para hacer una pintura negativa de sus adversarios. Atacó fieramente al grupo de base de la ARIC y los acusó de usar las camionetas para transportar delegados ejidales a las elecciones y de usar fondos de la organización para ofrecer mordidas a cambio de votos. Reclamó que esta clase de corrupción tenía que parar y que Núñez en contraste no gastaría un simple peso en su propia campańa. (Xavier y Uribe trata- 
ban de reelegirse al final del año y requerían el apoyo de Núnez contra el candidato respaldado por el grupo base de la ARIC). En el mismo mitin, un comisionado de otro ejido continuó con las recriminaciones contra el grupo antagonista de la ARIC y estableció que él no quería tener nada que ver con gente como El Güero, Gerardo Soto, Humberto Leal y sus seguidores. "Núñez los había confrontado y no les temía. Si solo Gerardo Soto (el líder de la ARIC) tuviera más visión. Pero este no es el caso y por lo tanto es necesario el cambio. Este cambio es provisto por la planilla de Núneez". Después de éste, un joven subió al estrado para enfatizar la necesidad de la unidad entre los presentes. Dijo que el interés del gobierno era que los campesinos no se unieran, al contrario, que permanecieran desunidos.

Por la muchedumbre presente, era evidente que en su esfuerzo para capturar el CMC, Núñez había sido capaz de conseguir las alianzas de los dos grupos operando dentro del PRI y algunos otros grupos opositores. Esto último era notable dado que la contienda involucraba a una organización afiliada al PRI. A pesar de que la coalición era llamada Unidad Campesina, ésta permanecía frágil y carecía de identidad política o de una visión común sobre cómo abordar los problemas de los ejidatarios de la región. Esto intensificaba la necesidad de eventos públicos a través de los cuales unificar los grupos dispares y demostrar públicamente su apoyo. Por ejemplo, Domingo Xavier, un comisionado ejidal y exdiputado del PRD, había empleado sus habilidades como orador a favor de Núńez en un evento de la campańa organizado dos semanas antes y su ardiente discurso despertó una respuesta entusiasta de la audiencia. Además de las dimensiones discursivas, la representación cultural tenía también un impacto visual fuerte. Xavier aseguró haber sugerido a Bruno Nava como secretario de la planilla y que le tenía mucha confianza, lo que enfatizó luego con un firme saludo de mano. El acto físico y visible de estrecharse las manos expresaba el apoyo para el candidato de la alianza.

Varios de los organizadores de la campańa de Núńez caminaban alrededor nerviosamente, contando a los comisionados ejidales presentes y permitiendo su voto. Estuvieron corroborando una lista realizada a partir de los asistentes a dos eventos públicos anteriores. El evento realizado dos semanas antes en el auditorio de la CMC ha- 
bía disfrutado de una buena cantidad de delegados. Para atraer a los comisionados, Núnez y sus colaboradores promocionaron el mitin al correr la voz de que darían cerveza y birria de chivo, servidas muy frecuentemente en las ocasiones festivas y los eventos políticos. Al inicio del evento, se pidió a algunas de las pocas mujeres, de entre la muchedumbre de sombreros y cachuchas de béisbol, que sirvieran la birria en platos de plástico. Núńez y Uribe estuvieron activamente distribuyendo los platos desde el frente del escenario hasta el fondo del auditorio a los delegados que sentados esperaban pacientemente su comida. Núnez pidió a las mujeres servir porciones pequeñas porque estaba preocupado de que no hubiera suficiente para todos. Cuando Uribe abrió el mitin mencionó la poca comida y agregó que esperaba que la gente se sintiera satisfecha. La cantidad de comida contribuía claramente a la calidad del evento.

Con los estómagos llenos, la cerveza empezó a circular entre los asistentes. Uribe continuó con la presentación de los otros dos miembros de la planilla de Núnez. Los candidatos fueron aplaudidos entusiastamente y saludados con porras. La distribución de comida y bebida parecía energizar a la audiencia.

Mientras tanto, Núñez y Uribe tomaron sus asientos detrás de algunas mesas colocadas sobre una gran plataforma, frente al auditorio. Estaban rodeados por grandes carteles del PRI y la CNC. Todos estos elementos trabajaron para apoyar al candidato y autorizar su desempeño. En el presídium Núnez estaba acompañado por un ingeniero agrónomo, conocido localmente, que trabajaba para el gobierno federal y por otro funcionario que representaba la autoridad gubernamental y la experiencia ingenieril (Oré y Rap 2009). Uribe les agradeció su presencia. Señaló al güero alto sentado en la primera fila y me presentó como un ingeniero de Holanda, "aquí, en un intercambio de tecnología". Uribe se congratulaba por el hecho de que gente como "el ingeniero Eduardo hizo todo ese camino para cooperar con nosotros de la Margen Izquierda, gracias a nuestro presidente de la Margen Izquierda”. Me paré e incómodo saludé a la gente del auditorio que estaba aplaudiendo. Los detalles acerca de un supuesto intercambio de tecnología fueron creativamente usados por el orador con el fin de explotar políticamente mi presencia. 
Posteriormente, la audiencia escuchó una serie de discursos, empezando con Núñez y seguido por varios líderes ejidales. Los asistentes respondían aprobando con expresiones de entusiasmo, gritos, aplausos y bromas. Aunque el escenario estaba abierto para comentarios de la audiencia, muchos comisionados prefirieron no hablar en público. Un grupo selecto de líderes reforzaron el desempeño del candidato, no con palabras o actos físicos, sino mostrando su estatus, clase, experiencia y medios. Las intervenciones fueron hechas por los participantes con mayor elocuencia y experiencia política. Usualmente eran los más educados, y a juzgar por sus ropas y conducta, no carentes de medios económicos.

En el mitin, Núńez contó 142 votantes en su apoyo, más de los 109 requeridos, y concluyó que esto sería suficiente para ganar. Sin embargo, insistió a los comisionados ejidales de convencer a sus colegas para que acudieran a las elecciones, ya que necesitaban mayor apoyo para asegurar la victoria. Después del evento, los organizadores de la campańa de Núnez estaban optimistas, pero inseguros, ya que las lealtades de los delegados permanecían impredecibles hasta lo mero último. Estos mítines no eran necesariamente un indicador de la votación del día de las elecciones. Los delegados podían cambiar fácilmente de lado durante las semanas previas a la elección, a causa de un evento similar placentero o promesas de pagos, trabajos o favores que el grupo opositor podía ofrecer en este periodo. Al siguiente evento, sólo 80 gentes acudieron. Los organizadores llegaron a estar preocupados ligeramente por las dificultades de movilizar estos votantes para la siguiente ocasión. Como respuesta, Núñez apeló a que el interés y compromiso de la gente no debería disminuir para nada e insistió a sus amigos y parientes para que acudieran a votar la siguiente semana. Así, estos eventos electorales fueron esenciales para el negocio de atraer y monitorear votos. La calidad de la representación cultural estuvo siendo estimada con referencia a la atmósfera creada por los votantes presentes.

En el mitin posterior, los organizadores contaron 107 votos, con los cuales normalmente sería suficiente para ganar las elecciones. Sin embargo, ellos notaron la ausencia de varias gentes que se habían comprometido a acudir al desayuno y les preocupaban sus votos. 
Núñez deliberó con sus colaboradores sobre lo que habría que hacer y decidió enviar a Leopoldo con su camioneta a recoger a cierto comisionado que no había llegado. A pesar de todos los recursos monetarios, gastronómicos y de transporte empleados para atraer votantes, no podía asegurarse la victoria electoral.

La interpretación es una parte esencial de la representación cultural. En este respecto, la perspectiva de un extrańo es reveladora. Fuera del local inicié una conversación con el director de una escuela local agrícola de Villa Hidalgo. Él había venido a expresar su apoyo a Núñez, a pesar del hecho de que no podía votar. Como cualquier otro involucrado en la campańa, él se había movilizado para acarrear seguidores de Núñez desde los ejidos de la municipalidad de Santiago. Él había migrado recientemente a Nayarit desde el estado norteño de Sonora, así aunque era un recién llegado, había desarrollado un fuerte interés en las políticas relaciones en la región. Él me informó que la Alianza de Núñez estaba luchando contra un pequeño grupo de la Margen Derecha que siempre había dominado políticamente y distribuido los puestos del CMC, la municipalidad y la organización de productores de tabaco, ARIC. Me dijo que la gente de la Margen Izquierda del río había ejercido poca influencia en la política dentro de la municipalidad. Como recién llegado a la región, pensó que era notable que un río trajera tantas disputas. Sin embargo, a causa de que Núñez era apoyado por la mayoría de los ejidos de la Margen Izquierda y también había obtenido apoyo de varios ejidos de la Margen Derecha, podía esperarse que ganara las elecciones. El principal aspecto destacado de la representación cultural fue como el grupo político empleaba simbólicamente el río para crear divergencia con sus adversarios.

Mientras que discutíamos de política regional, Gonzalo Pérez arribó en su camioneta blanca. Empezó a saludar a la gente a nuestro alrededor, particularmente a los comisionados ejidales que conocía de la Margen Izquierda. Chocaba sus manos con fuerza como si les quisiera recordar un compromiso. El director susurró con admiración que este hombre era un diputado y que pertenece al grupo de Núñez, agregando que también era un gran productor privado. Pérez llegó hasta nosotros y estrechó nuestras manos firmemente. El 
director dialogó con Pérez acerca del supuesto de que este traería al secretario del ejido de Villa Hidalgo, pero no lo había encontrado. Daba la impresión de rendir cuentas a alguien que estaba detrás de la organización de la campańa. Pérez respondió que él mismo iría a Villa Hidalgo a buscar al hombre en cuestión y lo traería con él. Pérez representaba oficialmente a los productores privados de la Margen Izquierda; por lo tanto Núñez no podía afrontar ser identificado con él, porque representaban grupos con intereses contradictorios. Núnéz se abstenía de hacer públicas sus relaciones con influyentes políticos del PRI, tales como Pérez, Félix Torres o el gobernador. En los periódicos locales él negaba explícitamente tales relaciones y enfatizaba su lealtad primaria con el sector campesino, como opuesto a los terratenientes privados. Más tarde, el director me preguntó que si había notado las botas enlodadas de Pérez. Él pensaba que esto había sido deliberado, implicando que Pérez quiso mostrarse como un campesino ordinario, como los otros ejidatarios y no como un productor privado elitista. Al tener un papel en la sombra de este desempeño electoral, Pérez evitaba dar la impresión de estar involucrado en la campaña directamente. Sin embargo, su presencia y saludo de mano parecía recordar a varias personas su compromiso en la elección. También aspiraba a presentar una imagen particular de sí mismo para sus propias ambiciones electorales. Estos actos visibles y la imagen que producen son parte de una representación cultural.

Sin embargo, en el mitin, el centro del escenario era Núńez. Cuando el director y yo decidimos ir al interior, muchas de las mesas ya estaban ocupadas por los comisionados ejidales y sus acompañantes. Los primeros platillos de puerco, frijoles charros y tortillas, en platos de plástico, se estaban distribuyendo a los asistentes por el personal de la AUA y algunos de los organizadores de la campaña. Núńez mismo estaba completamente inmerso en el acarreo de platos para sus potenciales votantes. Él preguntó personalmente a varias personas sobre lo que deseaban comer y tomar. Con ceremonial cuidadoso recogía los platos de comida en la cocina y rápida y humildemente satisfacía sus deseos al traérselos personalmente. Nosotros nos dirigimos a la cocina y el director hizo notar, "como ves aquí están los jefes” seńalando a Fernando Gutiérrez, Mario Uribe, 
y Laguna, un canalero de la AUA, entre otros, que estaban sirviendo la comida desde las cazuelas a los platos y pasándolos a aquellos que entraban y salían de la cocina. Pregunté al director por qué el mismo Núnez se ocupa tanto al servir comida a todos y me explicó que eso muestra a Núnez como a la gente le gusta verlo. Al traer comida y bebida demuestra que es una persona abierta y al alcance de cualquiera. Yo agregué mi impresión de que Núñez deseaba ser visto como un servidor, una palabra que él había usado antes, y el director afirmó con la cabeza entusiastamente para confirmar mi impresión. Éste fue el clímax en el desempeño de Núñez. A través de este dramático acto de distribuir personalmente comida y bebida, trató de complacer a sus votantes y ganar sus votos.

Subsecuentemente, también demostró sus poderes de orador. Después de que la mayoría de los delegados habían finalizado su desayuno y parecían satisfechos, Núnez caminó a la plataforma de los oradores y empezó un discurso fiero en el cual señalaba a los delegados como compańeros y una vez como hermanos de clase. Prometió que cuando obtuviera la presidencia de la CMC no traicionaría su confianza y representaría en verdad sus intereses, particularmente aquellos de los productores de frijol y tabaco, no como los actuales CMC y ARIC quienes habían descuidado claramente los intereses campesinos. Núñez intentaba pelear por un precio justo para el frijol, el tabaco y otros cultivos. "Vamos a luchar por todos". Prometió progreso y bienestar para todos los campesinos. Luego afirmó que era necesario hablar fuerte al gobernador con el fin de hacerle notar sus necesidades. Prometió también que trabajaría para atraer compañías del exterior que generarían empleos en proyectos del gobierno e infraestructura, tales como el nuevo puente y la expansión del módulo de la Margen Derecha. Alegó que esto haría florecer de nuevo la agricultura, como en los días de La Costa de Oro, una referencia popular a las reminiscencias de ricas imágenes colectivas sobre los años de oro del cultivo de tabaco y la gran prosperidad rural de la costa norte de Nayarit antes de los ochenta. Con habilidades retóricas, el líder se vinculó a sí mismo con el pasado, el presente y el futuro de la región.

Esta representación cultural desató una respuesta de la audiencia. Núñez exclamó dramáticamente que era "ahora o nunca” y que 
era "tiempo de cambio". Clamó que los convencería con acciones y no con palabras. Ya que estaba totalmente comprometido, lo único que pedía era preguntar lo mismo a su audiencia: necesitaba el apoyo de cada uno. En respuesta a su poderosa voz, gestos expresivos y uso de lenguaje revolucionario, la audiencia se animaba cada vez más. Aplaudían y de tiempo en tiempo gritaban para expresar su aprobación. Al final de su discurso, Núñez pidió por la unidad. Al ganar las elecciones, afirmó, ofrecería a su oponente el puesto de secretario de la CMC con el fin de prevenir discordia innecesaria, una cosa aseguró en la que ya habían acordado entre ellos. Sin embargo, no dudaba que ellos tendrían la victoria. Para redondear su discurso alguien gritó "arriba la planilla verde", en apoyo del candidato de la lista verde. En respuesta, la audiencia aprobó y aplaudió entusiastamente. El desempeño de Núñez liberó pasión en la audiencia para su causa política.

La parte oratoria de su desempeño reforzó una respuesta emocional positiva generada por el disfrute de comida y bebida precisamente antes de ir a las urnas. Cuando el discurso de Núñez finalizó, la muchedumbre fluyó automáticamente al camino en procesión, con la bandera verde tomada desde su asta y sostenida en lo alto con triunfo. Núñez asumió la guía con su planilla detrás y sus seguidores. En su camino hacia el edificio de la CMC, pasaron la plaza principal de Santiago, que es el centro administrativo y político del pueblo. La caminata fue corta, y en sólo algunos minutos la procesión llegó muy temprano para la elección, debiendo los seguidores esperar en la sombra del camino del otro lado de la entrada. Los seguidores de la planilla roja llegaron en pequeńos y separados grupos. La procesión verde bajo su bandera unificó las diversas corrientes en la alianza y físicamente exhibía jerarquía y apoyo popular.

A las once en punto, se permitió la entrada al gran auditorio a las delegaciones de los comisionados ejidales votantes y pudieron registrarse para votar. Luego, la puerta del edificio se cerró detrás de ellos. Nadie quedó dentro del edificio, a excepción del presidente municipal, los representantes del PRI y de la CNC nacional. Mientras esperaban en la sombra por el resultado, los seguidores de la planilla verde emitían porras ocasionales a favor de su planilla, demostrando opti- 
mismo acerca de sus prospectivas de triunfo; los rojos permanecían callados al fondo. Fernando Gutiérrez funcionó afuera como centro nervioso de Núnez, coordinando los flujos de información entre los seguidores y comprando agua para aquellos que se decían sedientos. Después de más de una hora de espera, una oleada de porras salió del edificio del CMC, anunciando el resultado inminente: Núñez con 101 votos había ganado con una mayoría pequeña. Los seguidores verdes estaban evidentemente felices, sin embargo, se expresó ansiedad por lo inesperado de lo estrecho de la victoria. La muchedumbre del exterior de los seguidores verdes entró al edificio, mientras que la mayoría de los rojos permanecieron afuera. Núñez subió al estrado y dio un discurso de agradecimiento a sus seguidores. Después de él, el presidente municipal de Santiago y luego los representantes del PRI dieron sus discursos acentuando la necesidad de unidad y cooperación para el beneficio y progreso del campesinado. El cierre de la elección oficial hizo eco de las llamadas tempranas de Núñez por la unidad de los campesinos después de un periodo de discordia electoral.

Después de los discursos, los triunfantes seguidores se movieron hacia los campos de la feria de Santiago. Éstos están en la periferia del pueblo, designados para hospedar las festividades anuales. Se habían colocado varias series de mesas largas al aire libre para celebrar la victoria con un gran banquete para los delegados ejidales y agradecer el apoyo para Núnez y los candidatos verdes. Llegué cuando la fiesta estaba en su apogeo. La gran muchedumbre presente indicaba que aquellos atraídos por una comida gratuita con birria y cerveza habían interpretado libremente la noción de seguidor. Huesos de chivo desnudos de su carne, platos de plástico en el piso y colecciones de botellas vacías sobre las mesas reflejaban la euforia sentida por los seguidores de Núñez. El alegre canto de un apasionado comisionado ejidal a través del micrófono reforzaba esta impresión, para el entretenimiento de sus colegas en las mesas. Los miembros del personal de la AUA distribuían cervezas y consumían una o dos ellos mismos. En las alas de este espectáculo, un pequeño grupo de colaboradores alrededor de Núñez estaba discutiendo la victoria cerrada y especulando acerca de aquellos votos que inesperadamente no les favorecieron. Las celebraciones continuaron por horas hasta que se acabaron los 
cartones de cerveza y cada quien regresó a su casa. Este banquete espléndido que terminó con la representación cultural de Núñez sirvió para entretener, satisfacer y agradecer a sus votantes y seguidores.

\section{LOS IMPACTOS ADVERSOS DE LA REFORMA: EL USO POLÍTICO} DE LAS DISPOSICIONES DE RECURSOS

Este mitin fue más que un escenario transaccional, interactivo o coercitivo. También fue un escenario de actuación que funcionó implícitamente a través de su coreografía, secuencia de eventos y cualidades intrínsecas al generar un lazo afectivo entre el gran público y sus representantes (véase también a Adler Lomnitz et al. 2004). El alcohol, la comida y la música tuvieron una contribución importante en términos de producir tales estados de consciencia alterados (Bryceson 2002). El uso dramático de estos materiales culturales muestra que los recursos naturales y las relaciones sociales implicados no son manejados de una manera culturalmente neutral.

Sin embargo es un fallo postmodernista considerar sólo lo simbólico o los aspectos culturales exhibidos. Es precisamente lo que ocurre detrás del escenario de esta representación cultural lo que permite reflexionar sobre las reformas administrativas que dieron origen a estos eventos. Durante la campaña de Núñez, su grupo político se apropió de las disposiciones de los recursos -varios tipos de relaciones, tecnologías y flujos de recursos- cuyo acceso fue provisto por la AUA. La apropiación política de estas disposiciones afectó adversamente los recursos base de la AUA en varios dominios que fueron cruciales para su provisión de servicios. Esto contradice directamente las expectativas neoliberales a partir de las cuales se construyó la política de TMR. La idea central detrás de la devolución del manejo del riego y la creación de las AUA fue la estructuración de incentivos para asegurar un resultado óptimo. El incentivo principal de los usuarios era asegurar una entrega eficiente y efectiva de servicios y recursos. Sin embargo, el resultado de la AuA fue por debajo de lo óptimo. Ya que estos modelos administrativos estiman el manejo de los servicios como un acto técnico de provisión del servicio, el uso cultural de la disposición de los recursos de la AUA para fines políticos era inesperado. 
El mismo presidente Núñez nunca fue un real usuario del agua ni un campesino ordinario, pero había optado por representarlos políticamente. ${ }^{7}$ Aunque los usuarios del agua y los temas sobre el manejo del agua difícilmente aparecieron en su campaña electoral, la AUA llegó a ser su principal fuente de ingreso y fondos para la campaña. Oficialmente, él no recibía incluso un salario como presidente, pero la presidencia de la AUA le otorgaba la oportunidad de incrementar su presencia local y desarrollar un perfil como líder político. Todavía más, la oficina del edificio de la AUA era útil para recibir visitantes y realizar negocios en una atmósfera confidencial. Núnez tenía un escritorio especial para este propósito. Detrás de él, coordinaba su campaña para el cMc. Cuando recibía gente importante, exhibía la gran responsabilidad que implicaba el manejo del sistema de riego más grande de Nayarit. Daría órdenes a su personal, haría llamadas urgentes, dispensaría favores, tomaría decisiones acerca de grandes sumas de dinero y por lo tanto mostraría la posición influyente que disfrutaba como presidente. Desde esta posición movilizaba diferentes disposiciones de recursos sociales, organizativos y materiales para construir una alianza política más amplia.

\section{Relaciones sociales y organizativas}

La alianza política de Núñez consistía de un círculo cercano y uno más amplio. Fue construida primeramente a partir de relaciones sociales cercanas de amistad, parentesco, compadrazgo (parentesco ritual), y vecindad del grupo político de Núñez en la Margen Izquierda del río Santiago. Las relaciones clientelistas en este grupo fueron mantenidos no solamente por interés material, pero también por variables culturales como la confianza y el "cuatismo" (Lomnitz 1977; Adler Lomnitz 1994). Alrededor este círculo cercano, se desarrolló un círculo más extendido de vínculos débiles con líderes locales y seguidores que apoyaban a la planilla verde de Nuńez a cambio de prestaciones, favores y servicios personales. Estas afinida-

${ }^{7}$ Aunque inicialmente poseía un terreno de pocas hectáreas en el ejido Solorceño, no lo cultivaba él mismo sino que lo rentaba e incluso más tarde lo vendió. 
des y compromisos eran de otra duración (Hernández Rodríguez 1997). Además de las relaciones sociales, organizativas y materiales inmediatos, el apoyo para la alianza se basó también en promesas, proyecciones, ilusiones y esperanzas falsas. Después de las elecciones se produjo un alejamiento en la alianza porque varios trabajos y favores prometidos no se concretaron. Sólo un mes después, el líder aliado, Domingo Xavier, se peleó con Núńez en una cantina y fue citado en la prensa: "Me equivoqué con Núnéz". Entonces, detrás de una alianza aparentemente unificada existían engaños políticos, dobles juegos, abusos de poder y actos ilegítimos. Para prevenir que las desconfianzas y desacuerdos salieran a la luz del día antes de ir a las urnas, la alianza organizaba varios actos electorales de unidad para realizar y visibilizar una cohesión, aunque de carácter temporal y frágil. Además, tenían otros recursos a su disposición.

\section{Distribución del agua}

El agua era indudablemente un recurso político. El grupo político de Núñez garantizaba el acceso privilegiado del riego a varios grandes y favorecidos productores a través de los miembros del personal que operaban la infraestructura del canal de la Margen Izquierda. Esto se hizo a cambio de un pago informal que al no tener que ser reportado se invirtió directamente en la campaña. ${ }^{8}$ A causa de la abundancia relativa del agua, los efectos de esta práctica no fueron extremadamente serios para los otros productores y ejidos. Aun así, el uso del agua como recurso político estaba restringido. Es decir, las redes de canales en la Margen Izquierda y en la Derecha son independientes una de la otra. Por ello, el grupo de Núńez no podría hacer uso de la distribución del agua para construir apoyo político en la Margen Derecha. El hecho de que estas condiciones se diferenciaran de la mayoría de otros distritos de riego mexicanos, donde el agua es escasa, indica por qué en este caso, el uso de la maquinaria de mantenimiento fue crucial como arma política para la campaña de Núnez.

${ }^{8}$ La razón detrás del acceso a los privilegios gozados nunca fue meramente financiera, sino que estaba mezclada con relaciones de amistad, comercio y apoyo político. 


\section{Maquinaria de mantenimiento y obras públicas}

Un activo más interesante, política y comercialmente, fue la maquinaria de mantenimiento de la AUA. Especialmente en este escenario rural tropical con un alto índice de lluvias, causante de crecientes frecuentes y rápido desarrollo de la vegetación, tal maquinaria tiene alta demanda. La AUA controlaba una determinada cantidad de maquinaria móvil, como una dragadora, una excavadora hidráulica y varios camiones de carga para los cuales empleaba a un grupo confiable de operadores de mantenimiento. El grupo político movía las máquinas y sus operadores en línea con sus intereses políticos y financieros más inmediatos.

En primer lugar, las máquinas constituían un recurso importante para generar apoyo político y expandir el rango de la alianza política de Núñez hacia la Margen Derecha en el municipio. La AUA otorgó favores en forma de obras públicas a varios de los comisarios ejidales fuera del Distrito de Riego de la Margen Izquierda, los cuales tuvieron un importante papel para adquirir apoyo a la Alianza de Núnez. Estas obras públicas, como caminos públicos o un campo de fútbol, son fuentes apreciadas de legitimación y apoyo político para los líderes rurales que buscan mejorar su imagen pública entre su electorado. Segundo, el grupo también usó el mantenimiento de la maquinaria como una fuente ilegítima de ganancias para financiar la campaña. Los gastos de la campaña de Núńez fueron cubiertos por renta de la maquinaria a terceros privados quienes pagaron un precio por hora, cuando estas ganancias deberían haber sido contabilizadas para la AUA.

El impacto desafortunado del uso intensivo y político de la maquinaria fue que la infraestructura de la Margen Izquierda recibió mantenimiento insuficiente, las máquinas se deterioraron y los gastos sustanciales de reparación se descuidaron, dando como consecuencia que los camiones y máquinas quedaran inhabilitados por periodos largos.

\section{Movilidad politica motorizada}

El transporte era esencial para la movilidad política y la movilización electoral. La AUA tenía a su disposición una flotilla de motocicletas y 
vehículos operados por su personal, cuya lubricación y gasolina provenía de los flujos económicos de la AUA. Antiguamente la movilidad política y la movilización popular estaban fuertemente restringidas a los funcionarios del gobierno o del partido y a los productores ricos. El día de la elección esta flotilla hizo posible la transportación de gran cantidad de votantes potenciales desde los ejidos más remotos para el evento electoral en Santiago. ${ }^{9}$ Es decir, los servicios de transporte para los votantes a las casillas fueron esenciales en la victoria de las elecciones del CMC. Antes y después de las elecciones, el presidente de la AUA, Núnez debía su movilidad a su acceso de tiempo completo a su camioneta pick up. Por ello pudo transportar rápidamente, desde su base en la Margen Izquierda, a la Margen Derecha, a la otra parte de su electorado. Esto fue absolutamente esencial para su trabajo electoral en el municipio. Los organizadores de su campaña, que incluían a muchos del personal de la AUA, pudieron moverse también por el municipio sin perder mucho tiempo. De esta manera, fueron capaces de organizar una serie de encuentros festivos con seguidores potenciales y construir una alianza para las elecciones venideras. Aún más, fueron capaces de tener acceso a la capital del estado, Tepic, necesario para el cabildeo del gobierno estatal.

\section{Administración de ganancias financieras}

La apropiación de recursos de la AUA para propósitos electorales tuvo un claro efecto negativo en el estatus financiero de la institución. Durante la campaña de CMC, las ganancias provenientes de los pagos del riego para el ciclo principal rápidamente se evaporaron, mucho más pronto que en otros años. Casi a la mitad del ciclo principal de riego en marzo de 1990, justo después de las elecciones, la AUA experimentó severos problemas de efectivo, con el resultado de que los pagos de salarios y otros gastos se pospusieron por varios meses. Debido a ello, la AUA tuvo que pedir un préstamo bancario, hipotecando

${ }^{9}$ Esta práctica es muy similar a la manera en que se acostumbraba y acostumbra a que los automóviles, personal y recursos del gobierno fueran movilizados y financiados desde fondos no gubernamentales obtenidos desde una AUA. 
sus propiedades, el cual terminó pagando hasta el próximo ciclo de riego (1998/1999). Después de llegar a presidente del CMC, Núñez incrementó su radio de acción política, a pesar de que el CMC por sí mismo resultó tener pocas fuentes de recursos. Los grupos políticos en control de la ARIC y del municipio, que se vieron derrotados en esta campaña electoral y temían la candidatura de Pérez por la municipalidad, detuvieron su apoyo financiero al CMC. Por esto, durante el último año de Núñez en la oficina (1999), el balance de la AUA fue negativo por primera vez en varios años. Todos estos factores condujeron al descontento y un criticismo más abierto entre los delegados y el personal por el manejo político y corrupto en la AUA, la Comisión Nacional del Agua y el gobierno estatal.

\section{Cambios políticos, administrativos y eCONÓmicos EN EL CAMPO}

Aunque este patrón de distribución de recursos revela continuidades con políticas públicas previas de manejo del riego, difiere en que este ocurrió en un contexto de cambios políticos, administrativos y económicos mayores. El desempeño electoral de Núñez no fue una reproducción mecánica o instrumental, sino una reinterpretación creativa de repertorios culturales existentes en una situación nueva en la que el manejo del recurso y la conducta política estaban menos controladas desde el centro - una situación que reforzaba tanto la necesidad como la oportunidad de una nueva representación cultural-. Los cambios políticos que esto indujo incluyeron el decline de la hegemonía del PRI y el debilitamiento de sus organizaciones corporativas. En muchas regiones de México, la victoria electoral del PRI era menos segura que nunca, particularmente ocurría en la costa norte de Nayarit que tiene una historia de votante por la oposición de la izquierda. ${ }^{10}$

${ }^{10}$ Dos elecciones destacan esto. En 1975, Alejandro Gascón, quien tuvo una fuerte base de apoyo en la Costa Norte, ganó la elección para gobernador del estado por el Partido Popular Socialista (PPS). El PRI no reconoció la victoria. Más tarde, en 1993, el partido de izquierda, PRD, movilizó de manera efectiva el descontento popular de la Costa Norte por la privatización de Tabamex y el decline agrícola general. El PRI reconoció la victoria del PRD sólo en la Margen Izquierda del río Santiago. 
En una arena política cada vez más competitiva, las políticas públicas neoliberales habían cambiado la economía política de la producción del tabaco, la organización rural, la política regional y condujeron a la emergencia de "nuevos" actores organizacionales traslapados con comunidades electorales.

Sin embargo, estos amplios procesos políticos, administrativos y económicos no se desarrollaron nítidamente como se anticipó y resultaron en variaciones regionales significantes. En la costa norte de Nayarit, los grupos políticos que se apropiaron de las emergentes asociaciones de productores no eran realmente "nuevos" actores. Sus historias, redes y patrones descansaban en el PRI. Así como Tabamex y otras agencias burocráticas habían tenido un papel central en la vida política de Nayarit durante los setenta y ochenta, estas asociaciones de productores ganaron en importancia política durante los noventa, particularmente en las municipalidades rurales como Santiago. Lograron esto proponiendo candidatos para las posiciones electorales y dar apoyo político, organizacional y financiero para campañas de aliados políticos del PRI.

A pesar del decline general del corporativismo y de la pluralización democrática, la CMC de Santiago mantenía su importancia política. Por lo tanto, recibía apoyo financiero desde la rica ARIC y apoyo político desde el presidente del PRI. Esto le permitió continuar representado a los ejidos en sus relaciones con la burocracia y cuerpos políticos del estado. Como un espacio privilegiado de negociación, la CMC también mantuvo su acceso estratégico para ganar posiciones en la municipalidad y de manera más general para ascender políticamente. En el par de años previo, esta oportunidad había sido controlada por el grupo de la ARIC, el cual estaba ahora siendo retado por el grupo de la AUA de la Margen Izquierda del río Santiago. Como las elecciones de la CMC ocurrieron en el año en que habría una importante elección, fueron decisivas para el futuro de ambos grupos en la competencia.

Aún más, la reforma electoral no pudo deshacer las formas de asociación política. Aunque el caso presentado puede dar la impresión de que las elecciones locales tuvieron lugar sin que se involucraran niveles más altos de la política, no fue así. A través de su familia, 
Pérez tenía conexiones políticas con el grupo del influyente gobernador de Nayarit, don Emilio González. Como parte de un esquema mayor, este grupo político apoyó la candidatura de uno de sus protegidos, Félix Torres, presidente municipal de Tepic, quien se registró como uno de los seis precandidatos para gobernador de Nayarit.

\section{LA CONTIENDA ELECTORAL COMO UNA REPRESENTACIÓN CULTURAL}

En sentido general, el evento electoral incontrovertiblemente refleja las culturas políticas populistas, personalistas y regionales de México y porta pistas claras de las relaciones corporativistas y clientelistas que han dominado la política (PRI) desde la Revolución Mexicana. A un nivel más específico, el grupo político de Núñez exhibe un desempeño significativo y persuasivo en un repertorio cultural específico con el fin de apelar, enganchar y movilizar el apoyo entre su grupo blanco, el de los comisionados ejidales. Mi análisis se enfoca a seis elementos que son característicos del performance cultural descrito.

En primer lugar, el evento expone ambigüedad con respecto al papel de las políticas públicas en la política rural contemporánea. Ello no implica que las políticas públicas no sean importantes. Los mensajes políticos en los cuales se enfocó Núñez en su campaña se centraron en el estado deplorable de la agricultura de la región, los bajos precios de los cultivos, las pobres oportunidades de mercado y la inhabilidad del gobierno para resolver estos problemas. Como una estrategia electoral, tomó una fuerte posición contra la ARIC. De esta manera, movilizó el descontento general entre los cultivadores del tabaco y otros segmentos de productores de los ejidos del municipio. Estos temas de bajos precios y el mal funcionamiento de la ARIC eran preocupaciones generales entre los muchos campesinos y pequeños productores de tabaco, y fueron las bases alrededor de las cuales Núñez construyó su alianza de apoyo. Sin embargo, también era un aspecto de actuación hacia el público el retar tales temas de descontento general. De hecho, desde este nivel local poco puede hacerse para cambiar la economía política de la producción tabacalera, dadas las relaciones internacionales del mercado y el "triángulo 
de hierro" entre las empresas tabacaleras multinacionales, el gobierno mexicano y la ARIC. Sin embargo, los temas que enfatizaba Núnez en representación de su electorado claramente no eran únicamente las bases para construir alianza política y ganar apoyo popular. Esto se confirma en el resto del análisis.

En segundo lugar, Núńez mantiene un discurso estatal muy convencional que enfatiza la necesidad del apoyo gubernamental para el campesinado. El único elemento nuevo es, tal vez, su proclama para atraer compañías de fuera de la región para crear empleos. Esto es entendible, ya que es la razón de entrada del órgano corporativo que desea representar. Las demandas de Núnez por un retorno a las políticas redistributivas, como el apoyo federal para el precio de los productores de frijoles, y su atención a la construcción de grandes obras de infraestructura en el municipio parecen fuera de época en tiempos de abandono del estado, pero deben ser entendidas en el contexto de la proximidad de las elecciones para gobernador. Durante este periodo, el PRI dio lo mejor de sí para recuperar el apoyo electoral siguiendo las líneas establecidas de dar subsidios y apoyos a grupos específicos de las clases populares, así como obras de infraestructura con importancia simbólica para el desarrollo regional. Esto creó algún espacio para la negociación, la representación de intereses y la exhibición pública para los representantes del PRI, tales como Pérez y Núñez.

En tercer lugar, a pesar del enfoque hacia las virtudes del líder, este es dependiente del grupo político y su amplia alianza. Al tener un papel central durante los eventos de la campańa, Núnez manifiesta su liderazgo político sobre la alianza que él y sus colaboradores han unido. Los mítines de la campaña sirvieron como ocasiones especiales para conmemorar las buenas maneras del líder, sus valores y puntos fuertes. El desempeño de Núńez acentuó su liderazgo personal y escondió el hecho de que era parte de un grupo político y alianza de apoyo que organizaba sus eventos electorales. Durante toda la campaña, su grupo político exhibió una división mutua de tareas y credenciales culturales para la organización de los eventos y la movilización de los votantes. Este es el resultado de una capacidad y de la distribución de trabajo en un colectivo más amplio. Por ejemplo, el personal de campo de la AUA se encargó de la organización básica para Pérez y 
Núñez. A nivel gerencial, Gutiérrez y Pérez estuvieron activamente involucrados en la coordinación de la campaña. Aunque Pérez se quedó conscientemente en la sombra, él es el patrocinador de Núnez y él lo había educado y financiado en su carrera política.

Cuarto, hay un contraste interesante incorporado en el tipo de liderazgo que Núńez interpreta en público - un contraste que por una parte acentúa servidumbre y humildad y por la otra autoridad-. Núñez es presentado por sí mismo y por otros con un líder honesto con antecedentes de campesino pobre que representa a una amplia e imaginaria masa de campesinos y ejidatarios. Sin embargo, este enfoque modesto para representar su base electoral coexiste con la imagen contrastante de un líder autoritario. El cambio que promete hacer Núnez, la confianza que exhibe acerca de su victoria en las elecciones, su "firme postura" ante el gobernador y sus oponentes, su lenguaje carismático y expresivo, por no mencionar su elocuencia, contribuyen todos a la misma impresión. Además, varios miembros de la alianza refuerzan el machismo público al glorificarlo en un lenguaje cargado sexualmente como un potente y entusiasta líder que no teme a sus oponentes, de cuya masculinidad se burla. Humildad y autoridad son claramente dos caras de la misma moneda; ambas apelan a los ideales de la gente acerca del carácter del líder y, como resultado, la gente es capaz de identificarse con la candidatura de Núnez.

El líder habilidosamente se conecta a sí mismo con las fuentes populares de la autoridad política y la demanda pública. Núñez se sitúa a sí mismo como un eslabón vital en la transición del pasado rural al futuro. Su lenguaje revolucionario y los símbolos que lo rodean reviven recuerdos populares colectivos de un pasado regional próspero y traen a la mente un campesinado revolucionario históricamente unido en la lucha nacional por la tierra y la libertad. Aunque esas imágenes pueden haber caído en desuso en otras partes del PRI, Núnez apela a las facciones izquierdistas que son parte de su alianza. Más aún, al generar esperanza por un futuro mejor, Núñez se refiere a nuevos programas del gobierno, grandes obras de infraestructura y compañías del exterior. Asociados con él, hay otros con autoridad gubernamental, experiencia agronómica y avanzada tecnología foránea. El acto simbólico de Núnez como líder de la alianza 
alcanza su cenit cuando camina al frente de la procesión en dirección a las casillas, con sus colaboradores y seguidores detrás de él. Este ritual representa el orden jerárquico y la unidad de su alianza.

En quinto lugar, para ganar credibilidad como un líder político, Núnez alterna entre sobajar a sus oponentes y reconciliarlos con él. En el camino a la elección, Núñez lanza una campaña de denuncias para ensuciar el nombre del grupo oponente, la ARIC. Los severos ataques morales sobre la corrupción de sus oponentes revelan un aspecto irónico de su desempeño. El presidente de Sanidad Vegetal critica fieramente a sus adversarios por el uso de recursos institucionales en la campańa, descuidando el hecho de que él y Núñez estaban haciendo exactamente lo mismo. Sin embargo, característico de los políticos del PRI seguros de su victoria, al final de la campaña giran hacia la petición de unidad y el consenso y la reconciliación de diferencias con sus oponentes. Más aún, una señal que Núñez envía al gobernador y al partido es que él es un líder con un apoyo significante que el PRI no puede darse el lujo de perder. Pasarse a la oposición ya no es tan inconcebible como lo fue en el pasado (Klesner 1997).

Finalmente, al ofrecer personalmente comida y bebida a sus votantes potenciales, Núnez proyecta una representación cultural y una imagen de un líder comprometido para apadrinar y cuidar las necesidades individuales de sus seguidores, al distribuir personalmente los recursos que controla por su posición. Además, enfatiza el hecho de que es Núnez en persona, quien los provee con estos placeres, de quien ellos deben estar agradecidos. A través de este acto, Núnez recuerda a varios individuos y comisionados ejidales sus complicidades mutuas desarrolladas en encuentros festivos anteriores, por ejemplo, a través de la promesa de un favor o un empleo. La provisión, consumo colectivo y el disfrute de comida y alcohol implica cierta reciprocidad y nutre las relaciones de confianza y cuatismo. Sin embargo, al mismo tiempo, la distribución pública de comida y bebida destaca la apropiación privada y la redistribución personalizada de recursos en los cuales se basó parcialmente la alianza. Esto revela la representación cultural como un ritual atado a la corrupción en una manera que es similar, pero distinta, de la ilustrada por el trabajo de Gupta en la India. Para la amplia audiencia, sin 
embargo, este acto posicionó a Núñez como el líder legítimo merecedor del apoyo popular. Después de su elección e inauguración, Núńez recompensó a sus seguidores con el mismo estilo y celebró su éxito con un gran banquete con alcohol, comida y música en vivo.

La contienda electoral final fue una interpretación orquestada en la cual grupos dispares fueron unidos en una amplia alianza y orientados a votar por su líder de una manera culturalmente específica. Primero que nada, el prospecto ampliamente anunciado de tal disfrute atrajo gran audiencia de votantes potenciales desde todos los rincones del municipio. En segundo lugar, esto trabajó activamente para relacionar a los comisionados ejidales individuales en una gran alianza colectiva, que al iniciar la campaña estaba sumamente fragmentada. En otras palabras, la experiencia colectiva hizo sentir a los comisionados como parte de una alianza. Aunque comer y beber son actividades corporales, el consumo de comidas regionales y bebidas también incorpora al individuo a un todo geográfico y simbólico. El evento portó así un sentido de identidad común, unidad y propósito para la alianza, mientras que enmascaró las divisiones sociales existentes. En tercer lugar, las pasiones colectivamente compartidas tienen un papel mayor en el establecimiento de la conexión emocional entre el líder y sus masas y puede incrementar el resultado electoral favorable. El evocar, canalizar y capitalizar las emociones colectivamente experimentadas, tales como el disfrute, la camaradería y la euforia de pertenecer a una alianza victoriosa, tiene el efecto de fortalecer la coherencia de la alianza. No fue accidental que los organizadores monitorearan cuidadosamente la atmósfera de los eventos como reflejo de las respuestas emocionales de la audiencia, tales como aplausos, risa y satisfacción. El número de delegados bien dispuestos con la atmósfera de convivencia entre ellos hizo que los organizadores se sintieran confiados en su victoria. Al unirse lo emocional con lo político, el desempeño de este acto relacionó al individuo con lo colectivo y su líder de una manera culturalmente específica.

El evento electoral de Núñez no fue único, y refleja un registro culturalmente específico que es producto de la historia (política) regional y nacional. En primer lugar, la historia de la costa norte de 
Nayarit ha estado ligada íntimamente a la producción de tabaco. Durante los cincuenta y parte de los sesenta la región experimentó una gran expansión agrícola y, en particular, el tabaco fue el cultivo más redituable. La gente acostumbra llamarlo "oro verde", lo que le dio a la costa norte su glorioso nombre, La Costa de Oro. A la fecha, los productores de tabaco recuerdan aquellos días de plenitud. Tales memorias están conectadas con el disfrute de tipos regionales de alcohol, comida y música. Cuando la gente desea expresar cuánto dinero ganaba en aquellos días te cuentan que las cantinas de la región estaban repletas los días de pago de las compañías. Incluso los ejidatarios de medios modestos contrataban grupos de mariachis que tocaban toda la noche para ellos, mientras que bebían cerveza hasta que quedaban dormidos sobre la mesa. A los políticos como Núnez, también les gusta referirse a este pasado colectivo mitificado de la Costa de Oro. Éste se corresponde con las visiones de los viejos tiempos de abundancia en la región y también sostiene una promesa para el futuro.

En segundo lugar, en Nayarit, como en muchos otros estados de México, los líderes políticos tienen una tradición popular de apadrinar las festividades públicas. Durante estas reuniones las muchedumbres son alimentadas con cerveza y especialidades locales, adornadas con discursos revolucionarios y presentaciones musicales en vivo. $\mathrm{Du}-$ rante tales eventos en el pequeño estado de Nayarit, muchos políticos, incluso el gobernador, pueden ser contactados de manera personal para discutir y resolver necesidades de la gente ordinaria. La organización de estos eventos públicos, particularmente durante el tiempo electoral, es un medio central para adquirir apoyo electoral para el gobierno del PRI, así como para otros partidos políticos. Núnez obtuvo tales habilidades culturales a través de un entrenamiento político implícito de sus patrocinadores, Pérez y Félix Torres. Ellos, en su momento, emularon el estilo político y las cualidades de liderazgo del patriarca de la política de Nayarit, don Emilio González, quien más tarde llegó a ser presidente del Senado con el presidente Salinas. Con un estilo personalista y populista característico de un gran patrón, incorporó, unió y controló una diversidad amplia de actores políticos, fuerzas y grupos bajo el PRI y significativamente dio forma a la cultura política de este pequeño estado. Hacia el fin de su vida, sin embargo, 
crecieron las divisiones facciosas entre varios de sus protegidos y otros contendientes por su sucesión, los puestos de gobierno, el PRI y sus bases institucionales corporativas. La disputa electoral narrada antes era una expresión de este desorden creciente en el partido que se acercaba al fin de su dominancia.

Por su parte, don Emilio fue influido por el populismo de su propio patrocinador, Fidel Velásquez, líder nacional de la unión corporativa de los trabajadores, La Confederación de Trabajadores de México (Стм) por más de medio siglo (1941-1947, 1950-1997), y por la política popular de Alejandro Gascón quien fue presidente de Tepic entre 1972 y 1975 y que ganó las elecciones para gobernador de Nayarit por el Partido Popular Socialista (pPs) en 1975. Aunque el PRI nunca reconoció tal victoria y reprimió fieramente a la oposición durante los siguientes seis años, durante su tiempo como gobernador entre 1981-1987, don Emilio adoptó elementos de las política popular de Gastón con el fin de recuperar estabilidad política y apoyo entre la población. La ironía de esta situación es que el patrocinador de Gascón fue el predecesor de Fidel Velásquez y primer líder de la Стм, Vicente Lombardo Toledano quien rompió con el PRI para formar el Partido Popular en 1948 (más tarde el PPS). Un poco más tarde Fidel Velásquez expulsó a Toledano de la СTM. Esta historia regional y nacional sugiere también que la representación cultural es relevante más allá de la política local.

\section{Conclusión}

Este artículo ha ilustrado como, bajo la influencia de las reformas neoliberales, repertorios culturales y patrones de asignación de recursos, que son producto de una historia política regional y nacional, se renuevan en un nuevo escenario político, administrativo y económico. Estos hallazgos indican la naturaleza problemática de las teorías tecnocráticas que asumen que tales reformas son apolíticas, ahistóricas y vacías de cultura. Para presentar este argumento, el artículo ilustró lo que ocurre en un caso de reforma particular.

El caso analizado demuestra que las habilidades de interpretación pública y las formas culturales para expresarlas son centrales para la 
empresa política. Sin embargo, ya que la política no es sólo un juego simbólico, se ha mostrado también que esto está conectado con una lucha regional por el poder y los recursos. Un grupo político captura una institución local y la usa como su plataforma política al apropiarse de sus recursos con fines electorales. En apoyo de sus ambiciones políticas para atraer electores, el grupo hace uso de los recursos que provee la AUA, como el agua, personal, maquinaria, clientes, vehículos, obra pública, dinero, alcohol, comida y música. Esta gama de asignación de recursos sirvió para organizar una campaña política en la forma de una serie de encuentros públicos que aspiraban a movilizar el apoyo de la base popular. Esto permitió a Núñez construir una alianza amplia de apoyo entre los comisionados ejidales que retó a la autoridad de la ARIC como la organización de productores dominante en la región. Además, estos recursos habilitaron a Núñez, su comitiva y empleados para organizar y ejecutar tres mítines políticos para asegurar el apoyo público. En estos mítines, la distribución de comida y cerveza entre los votantes potenciales adquirió una importancia cultural y política central.

El artículo ha mostrado el potencial metodológico y conceptual del análisis situacional para el debate antropológico e histórico sobre la cultura política y el caciquismo en México (Roth-Seneff 2003). En el trabajo clásico de Paul Friedrich se puede apreciar como "los Príncipes de Naranja" usan su conocimiento de la cultura tarasca para legitimar su papel de lideres políticos (Friedrich 1986). Una potencialidad del análisis situacional y la observación etnográfica de líderes políticos en eventos y prácticas electorales es que muestra que la legitimización está en hacer evidente ese conocimiento a través de la representación cultural, porque permite verbalizar, visibilizar e imaginar las calidades de un liderazgo. Capturando un líder político "en vivo", nos muestra además como su "trabajo” y “juego", la vida organizacional cotidiana y su figura pública están inextricablemente unidas (Middlebrook 2009, 423). He enseńado entonces que la representación cultural de un líder no sólo tiene impactos simbólicos, sino también materiales y concretos para la representación organizacional y tecnológica de las organizaciones involucradas (McKenzie 2001). 
No ha sido mi intención argumentar que todas las formas de instituciones locales están destinadas a ser pervertidas por la política, aunque la clase de política examinada aquí parece particularmente corroída, lejos de cualquier manejo de recursos equitativo, democrático, justo o sustentable. Esto no es argumentar que esta forma de politización del manejo de recursos es un fenómeno necesariamente generalizado en las instituciones locales de México, pero ciertamente no se trata de algo nuevo o excepcional. También es necesario enfatizar que las habilidades de interpretación pública por sí mismas no garantizan la continuidad en el poder; la mayoría de los actores, discutidos aquí, perdieron poder posteriormente y varios cambiaron de partido cuando el PRI perdió las elecciones. No obstante, los repertorios culturales se reproducen y renuevan en el contexto de los cambios administrativos y los nuevos escenarios políticos. La elección de un gobernador "no priista" Antonio Echeverría en 1999 y después las elecciones federales de 2000 en que ganó Vicente Fox del PAN, ha cambiado la interrelación de fuerzas, multiplicado las opciones políticas, y creado nuevos escenarios para las culturas políticas regionales. Sin embargo, estos cambios no han disminuido (sino aumentado) la necesidad de representación cultural en hacer política. Estos cambios resultan frecuentemente en una variedad de resultados regionales en la distribución y flujo de poder político y recursos.

El análisis situacional y la etnografía de la representación cultural presentados aquí proveen una ilustración de tres fenómenos que reciben atención creciente en la literatura "de lo político": cultura y vida organizacional cotidiana, el rol del ritual, y el papel que la pasión tiene en la política. El permitir a la política reentrar en el análisis del manejo de recursos tiene otra gran ventaja, que ayuda a la normalización de la política. Esto se conecta con un cuerpo creciente de literatura que está saliendo de una perspectiva centrada en el Estado hacia un enfoque más descentrado que incluye a la cultura y las prácticas organizacionales cotidianas para el entendimiento de la política $(\mathrm{Ru}-$ bin 1997; Aitken 1999; Knight y Pansters 2005). La línea de análisis presentada aquí contribuye a tres pistas de esta literatura: primero, que su argumento se refuerza en una era de descentralización política, pluralidad democrática y desregulación agrícola; segundo, que una 
perspectiva cultural y performativa del poder es relevante para los escenarios administrativos; tercero, que el incremento del control local y regional sobre los recursos, previamente en manos del gobierno federal, abre espacios para la movilización política descentrada. Por supuesto, esto no ocurre sólo en las AUA, sino que es generalizado. Si éste es siempre necesariamente un acontecimiento positivo en términos de mejorar la asignación de recursos depende de cuales actores o fuerzas políticas emergen para ocupar estos espacios y la manera en que ellos hacen uso, se acomodan o renuevan repertorios culturales existentes.

En segundo lugar, al analizar el evento final de la elección como una representación cultural se ha ilustrado como se movilizan los recursos políticamente, no simplemente de una manera instrumental, sino también de acuerdo a maneras culturalmente apelantes, significativas y enganchadoras en la política. Esta perspectiva coincide con un acontecimiento en la literatura contemporánea que enfatiza el papel del ritual en la política mexicana. Desde mi entendimiento, la representación cultural es un tipo particular de ritual que permite un grado de imaginación creativa e innovación para los actores que interpretan y para sus espectadores. Varios autores muestran convincentemente que el ritual es central para la cultura mexicana (Beezley 1994; Lomnitz 1995). A través de la historia colonial y postcolonial, regímenes autoritarios sucesivos han restringido las esferas públicas y la discusión política promoviendo así el ritual público "como una arena donde las decisiones políticas se negocian y promulgan". En el punto de vista de Lomnitz, "la importancia del ritual, de las festividades, y las acciones redistributivas que se asocian con ellas", está históricamente ligada a la expansión del Estado y a "las demandas conflictivas de grupos antagónicos locales" que esto genera (Lomnitz 1995, 20). Este artículo ha ilustrado que algo similar ocurre en circunstancias donde el Estado se constriñe, donde los grupos políticos locales luchan por el control, de las áreas de las políticas públicas y los recursos acompañantes, de una manera culturalmente específica y ritualizada.

En tercer lugar, la representación cultural muestra como las pasiones son movilizadas políticamente (Mouffe 2005, 25). Al distri- 
buir personalmente la comida y el alcohol entre sus seguidores, el líder prospectivo establece una conexión emocional al contribuir a un estado festivo de mente y cuerpo. Esta excitación positiva se canaliza luego como un flujo de pasión que sirve para una causa electoral. Tal uso político de la pasión con seguridad no es nada nuevo. Aristóteles ya discernía entre tres formas de persuasión: logos (razón o la argumentación), ethos (carácter, credibilidad, reputación) y pathos (emoción). Entonces, como se ilustró aquí, la política y las políticas públicas no pueden ser reducidas a un ejercicio racional y discursivo (logos), sino que también involucra mostrar el carácter (ethos) y actos culturales que enganchen el cuerpo humano y emocionalmente el espíritu (pathos). En resumen, mi enfoque hacia la representación cultural genera una conclusión similar a la de Mouffe: "el error del racionalismo es ignorar la dimensión afectiva movilizada por identificaciones colectivas e imaginar que aquellas 'pasiones' arcaicas están destinadas a desaparecer con el avance del individualismo y el progreso del racionalismo" (Mouffe 2005, 6).

Para reforzar este punto de la pasión e ilustrar por qué la representación cultural tiene mucha relevancia más allá de la política local, necesitamos solamente recordar el día de Acción de Gracias del año 2003, más o menos un año antes de la elección, cuando el presidente Bush hizo una visita sorpresiva a los soldados americanos que recientemente habían tomado Bagdad. Frente a la prensa posó entre sus soldados vistiendo una chamarra militar. Desde una mesa cercana cogió y sostuvo un plato con un grande y hermoso pavo. Varios de los militares presentes tuvieron que sonreír como respuesta al jovial acto de su líder. Estas fotografías dieron la vuelta al mundo y generaron la impresión de que el presidente estadunidense estaba sirviendo personalmente este platillo típico para este día especial a los soldados que le han servido. Esto, para agradecer a sus compatriotas en nombre de la nación y conducirlos a la celebración del "éxito" de la política militar. Posteriormente, los funcionarios de la Casa Blanca admitieron que el ave era de plástico. El propósito de manufacturar tales eventos era para "poner a Bush en el escaparate", "dramatizar sus políticas agudamente" y transmitir sus cualidades reales. "Esto mostró que realmente él se preocupa por los soldados y 
se emociona cuando los ve" ${ }^{11}$ Esta "representación cultural del éxito de una política” (Rap 2006; 2008) reforzaba las encuestas domésticas y la moral militar. El dramático impacto de un presidente que alimenta a sus soldados exhibe como la pasión nutre a la política.

\section{BiBLIOGRAFÍA}

Adler Lomnitz, Larissa, Redes sociales, cultura y poder: ensayos de antropología latinoamericana, México, Facultad Latinoamericana de Ciencias Sociales, 1994.

Adler Lomnitz, Larissa, Rodrigo Salazar Elena, Ilya Adler, Simbolismo y ritual en la politica mexicana, México, Siglo XXI Editores, 2004.

Aitken, Robert, Localizing Politics: Cardenismo, the Mexican State and Local Politics in Contemporary Michoacán, tesis de doctorado, University of Leiden, 1999.

Barracca, Stephen, "Devolution and the Deepening of Democracy: Explaining Outcomes of Municipal Reform in Mexico", Journal of Latin American Studies, vol. 37, núm. 1, 2005, 1-28,.

Beezley, William H., Cheryl E. Martin y William E. French, Rituals of Rule, Rituals of Resistance: Public Celebrations and Popular Culture in Mexico, Wilmington, Scholarly Resources, 1994.

Bryceson, Deborah F., Alcohol in Africa: Mixing Business, Politics and Pleasure, Portsmouth, Heinemann, 2002.

De la Peña, Guillermo, Local and Regional Power, Austin, 1986.

Fallaw, Ben, "Dry Law, Wet Politics", Latin American Research Review, vol. 37, núm. 2, 2002, 37-64.

Friedrich, Paul, Los príncipes de Naranja: un ensayo de método antropohistórico, Austin, University of Texas Press, 1986.

Gledhill, John, Power and its Disguises: Anthropological Perspectives on Politics, Londres, 1996.

Goffman, Erwin, The Presentation of Self in Everyday Life, Nueva York, Doubleday, 1959.

${ }^{11}$ The Washington Post, diciembre 4, 2003, p. A33. 
Friedman, Milton, There is No Such Thing as a Free Lunch, La Salle, Open Court, 1975.

Gluckman, Max, Analysis of a Social Situation in Modern Zululand, Manchester, Manchester University Press, 1958.

Hernández Rodriguez, Rogelio, "Challenging Caciquismo: An Analysis of the Leadership of Carlos Hank Gonzalez" en Alan Knight y Wil Pansters, coords., Caciquismo in the Twentieth-Century Mexico, Londres, Institute for the Americas, 2005, 249-71.

Klesner, Joseph L., "Political Change in Mexico: Institutions and Identity”, Latin American Research Review, vol. 32, núm. 2, 1997, 184-200.

Knight, Alan y Wil Pansters, coords., Caciquismo in the TwentiethCentury Mexico, Londres, Institute for the Americas, 2005.

Lomnitz, Larissa' Networks and Marginality: Life in a Mexican Shantytown, Nueva York, Academic Press, 1977.

Lomnitz, Claudio, "Ritual, Rumor, and Corruption in the Constitution of Polity in Modern Mexico", Journal of Latin American Anthropology, vol. 1, núm. 1, 1995, 20-47.

McKenzie, Jon, Perform or Else: From Discipline to Performance, Londres, Routledge, 2001.

Middlebrook, Kevin J., "Caciquismo and Democracy: Mexico and Beyond", Bulletin of Latin American Research, vol. 28, núm. 3, 2009, 411-427.

Munro, Rolland, "The Cultural Performance of Control”, Organization Studies, vol. 20, núm. 4, 1999, 619-640.

Nuijten, Monique, Power, Community and the State: The Political Anthropology of Organisation in Mexico, Londres, Pluto Press, 2003.

OrÉ, Maria Teresa y Edwin RaP, "Políticas neoliberales de agua en el Perú: Entretelones y Antecedentes de la Ley de Recursos Hídricos”, Debates en Sociología, vol. 34, 2009, 32-66.

Pansters, Wil, "Goodbye to the Caciques? Definition, the State and the Dynamics of Caciquismo in Twentieth-century Mexico" en Alan Knight y Wil Pansters, coords., Caciquismo in the Twentieth-Century Mexico, Londres, Brookings Institution Press, 2005. 
Parkin, D., L. Caplan y H. Fisher, coords., The Politics of Cultural Performance, Oxford, Berghahn Books, 1996.

Rap, Edwin, "The Success of a Policy Model: Irrigation Management Transfer in Mexico", Journal of Development Studies, vol. 42, núm. 8, 2006, 1301-1324.

, "Produciendo el éxito en la política pública: la transferencia del manejo de riego en México", Revista de Estudios Sociológicos, vol. 26, núm. 77, 2008, 249-285.

Roth-Seneff, Andrew, "Caciquismo: el pasado en el presente", Relaciones. Estudios de Historia y Sociedad, vol. xxıv, núm. 96, 2003, 11-15.

Rubin, Jeffrey W., Decentering the Regime: Ethnicity, Radicalism, and Democracy in Juchitán, Mexico, Durham, 1997.

SNYDER, Ronald, "After Neoliberalism: The Politics of Reregulation in Mexico", World Politics, vol. 51, núm. 2, 1999, 173-204.

Thompson, Margaret, "The Politics of Cultural Performance", American Anthropologist, vol. 99, núm. 2, 1997, 416-417.

Turner, Victor, The Anthropology of Performance, Nueva York, PAJ Publications, 1987.

Velsen, Jaap van, "The Extended case Method and Situational Analysis" en A. L. Epstein, coord., The Craft of Social Anthropology, Londres, Tavistock, 1967.

VRIES, Pieter de, "Vanishing Mediators: Enjoyment as a Political Factor in Western Mexico", American Ethnologist, vol. 29, núm. 4, 2002, 901-927.

FeCha de RECEPCiÓn DEL ARTÍ́CUlo: 3 de diciembre de 2008

FECHA DE ACEPTACIÓN Y RECEPCIÓN DE LA VERSIÓN FINAL: 18 de mayo de 2011 